Revue

Revue de l'histoire des religions

de Ihistoire des religions

Genève, refuge et migrations ( $\mathrm{XVI} \mathrm{e}^{\mathrm{e}} \mathrm{XVII}{ }^{\mathrm{e}}$ siècles)

Poème judéo-hellénistique attribué à Orphée. Production juive et réception chrétienne. Traduit, présenté et annoté par Fabienne JoURDAN

Paris, Les Belles Lettres (« Fragments »), 2010

Ron Naiweld

\title{
OpenEdition
}

Journals

Édition électronique

URL : http://journals.openedition.org/rhr/8362

DOI : $10.4000 /$ rhr.8362

ISSN : 2105-2573

Éditeur

Armand Colin

Édition imprimée

Date de publication : 1 mars 2015

Pagination : 99-101

ISBN : 9782200929657

ISSN : 0035-1423

Référence électronique

Ron Naiweld, «Poème judéo-hellénistique attribué à Orphée. Production juive et réception chrétienne.

Traduit, présenté et annoté par Fabienne JouRDAN », Revue de l'histoire des religions [En ligne], 1 | 2015,

mis en ligne le, consulté le 22 septembre 2020. URL : http://journals.openedition.org/rhr/8362 ; DOI : https://doi.org/10.4000/rhr.8362

Ce document a été généré automatiquement le 22 septembre 2020.

Tous droits réservés 


\section{Poème judéo-hellénistique attribué à Orphée. Production juive et réception chrétienne. Traduit, présenté et annoté par Fabienne JOURDAN}

Paris, Les Belles Lettres (« Fragments »), 2010

Ron Naiweld

\section{RÉFÉRENCE}

Poème judéo-hellénistique attribué à Orphée. Production juive et réception chrétienne. Traduit, présenté et annoté par Fabienne JouRDAN, Paris, Les Belles Lettres («Fragments »), 2010, 306 p., $21 \mathrm{~cm}, 35 €$, ISBN 2-251-74206-9.

1 Ce livre est consacré à un poème attribué à Orphée, où ce dernier chante le Dieu unique dans des vers adressés à son fils, Musée. CEuvre d'un Juif d'Alexandrie du $\mathrm{III}^{\mathrm{e}}$ ou II $\mathrm{II}^{\mathrm{e}}$ siècle avant notre ère, ce texte est principalement connu par les sources chrétiennes des cinq premiers siècles, qui le citent dans un contexte du conflit idéologique et religieux avec la culture païenne du monde gréco-romain. Outre une présentation bilingue et commentée des trois rédactions du poème, Fabienne Jourdan propose une introduction éclairante sur les origines du poème et l'histoire de sa rédaction, sa transmission et sa réception par les auteurs juifs et chrétiens.

L'introduction comprend quatre parties.

3 Dans la première l'auteur s'interroge sur les raisons de la rédaction du poème et sur le milieu judéo-hellénistique où il a été produit. En effet, bien que la production littéraire juive en langue grecque avant Philon et Josèphe ne soit pas négligeable, il ne nous reste que peu de textes ayant eu la chance d'être cités par des auteurs chrétiens. La question du public auquel ce poème a été destiné doit donc s'inscrire dans une interrogation plus générale sur les raisons et les motivations de la production littéraire judéo- 
hellénistique de cette époque. Selon la thèse courante jusqu'à la seconde moitié du $\mathrm{xx}^{\mathrm{e}}$ siècle, cette littérature était destinée à un public païen dans une optique polémique ou apologétique. F. Jourdan, en revanche, participe à la réévaluation de cette thèse, et considère que les destinataires de cette littérature étaient des Juifs vivant dans un milieu païen. En règle générale, les compositions judéo-hellénistique avaient deux objectifs : répondre aux «besoins littéraires et philosophiques, voire apologétiques, de l'élite attirée par la culture grecque "; remplir le rôle d'un "instrument "politique" d'exhortation au courage ou à l'apaisement [...] un instrument commode pour guider les réactions de la communauté ». L'attribution à Orphée signale que le poème participe au genre pseudépigraphique, et $\mathrm{F}$. Jordan se livre à une discussion brève sur l'histoire et le sens de ce terme dans le contexte judéo-hellénistique. Elle évoque notamment la distinction introduite par W. Speyer (et reprise par M. Hengel) entre pseudépigraphie « authentique » et « fausse », en la critiquant.

Dans la deuxième partie de l'introduction sont discutées les citations des différentes rédactions du poème et de leurs sources. La première source est le traité De Monarchia, attribué à tort à Justin, mais qui a probablement comme auteur un Juif vivant entre le $\mathrm{I}^{\mathrm{er}}$ siècle avant notre ère et le $\mathrm{I}^{\mathrm{er}}$ siècle après notre ère. Il s'agit probablement du seul témoin juif, mais il est possible que le philosophe Juif Aristobule (II siècle avant notre ère), dans un passage qui nous est parvenu par Eusèbe, cite aussi quelques vers du poème. Le reste des citations provient des sources chrétiennes qui utilisent le poème dans un des trois objectifs suivants : prouver la présence entière et éternelle de la vérité judéo-chrétienne dès l'origine de la tradition grecque; exhorter les Grecs à la conversion; et témoigner de la malhonnêteté d'Orphée : bien qu'il ait connu la vérité monothéiste, il a choisi de se perdre lui-même ainsi que ses auditeurs dans l'erreur polythéiste (c'est le cas notamment de Théodoret et d'Augustin dans son Contre Faustus).

5 Suit la troisième partie consacrée à l'histoire de la rédaction et de la transmission du poème. En partant des critiques de Chr. Riedweg et de $\mathrm{C}$. R. Holladay sur la thèse de $\mathrm{N}$. Walter, F. Jourdan opte pour l'existence d'un poème originel qui a été remanié par les auteurs ultérieurs, juifs, et dans une moindre mesure chrétiens.

6 La dernière partie de l'introduction est consacrée à la question du titre du poème qui varie selon les sources qui le citent - Testament (Diathekai) ou bien Hieros Logos. Au lieu de trancher en faveur d'un des deux, F. Jourdain choisit d'y voir les traces de l'histoire de la réception du poème. Tandis que pour certains le poème a représenté le testament d'un Orphée converti au monothéisme, d'autres, comme Aristobule, choisissaient de rapprocher le poème à l'enseignement biblique, «afin vraisemblablement d'évoquer ce dernier par un terme familier à la pensée philosophique et religieuse païenne ». Après la présentation bilingue et commentée de trois rédactions du poème, le livre se termine par une annexe consacrée à la littérature judéo-hellénistique de la diaspora alexandrine $\mathrm{du} \mathrm{III}^{\mathrm{e}}$ au $\mathrm{I}^{\mathrm{er}}$ siècle avant notre ère.

7 Grâce à sa manière prudente et érudite de mener les discussions littéraires, philologiques et historiques, ce livre est précieux pour les chercheurs et les étudiants du judaïsme et du christianisme ancien. Il démontre comment un texte relativement court qui évoque plus de questions qu'il ne fournit de réponses et de certitudes, peut, avec un traitement scientifique minutieux et rigoureux, nous aider à mieux comprendre les relations complexes entre les deux religions monothéistes et la culture païenne du monde gréco-romain. 


\section{AUTEURS}

\section{RON NAIWELD}

Centre de recherches historiques (CNRS), Paris. 